\title{
Cancer pain management in China: current status and practice implications based on the ACHEON survey
}

This article was published in the following Dove Press journal: Journal of Pain Research

18 August 2017

Number of times this article has been viewed

\section{Zhongjun Xia}

Sun Yat-Sen University Cancer Center, Guangzhou, Guangdong, China
Correspondence: Zhongjun Xia Sun Yat-Sen University Cancer Center, No. 65I Dongfeng Road, East, Guangzhou, Guangdong 510060, China Tel +86 I36 027I 3223

Email xiazhj@sysucc.org.cn
Purpose: Cancer pain can seriously impact the quality of life (QoL) of patients, and optimal management practices are therefore of paramount importance. The ACHEON survey queried physicians and patients from 10 Asian countries/regions to assess current clinical practices in cancer pain management in Asia. This study presents the data obtained for cancer pain management in mainland China, with an emphasis on practices related to opioid drugs.

Materials and methods: In several tertiary hospitals across China, 250 patients experiencing cancer pain and 100 physicians were surveyed on questions designed to assess current cancer pain management practices and cancer pain impact on QoL.

Results: The patient survey showed that $88 \%$ of patients reported moderate-to-severe cancer pain, with a median duration of 6 months. The physician survey showed that medical school/ residency training with regard to cancer pain management was inadequate in $\sim 80 \%$ of physicians. A total of $80 \%$ of physicians and $67.2 \%$ of patients reported that pain scale was used during pain assessment; $84 \%$ of physicians expressed that physician-perceived pain severity was not completely consistent with actual pain the patient experienced. Of the 147 patients who recalled the medication received, $83.7 \%$ were administered opioid prescriptions. Of the 240 patients who received treatment, $43.8 \%$ perceived the inadequacy of controlling pain. The primary barriers from physicians perceived to optimal pain management included patients' fear of side effects (58\%), patients' fear of addiction (53\%), patients' reluctance to report pain (43\%), physicians' reluctance to prescribe (29\%), physicians' inadequacy of pain assessment (27\%) and excessive regulation of opioid analgesics $(47 \%)$.

Conclusion: Knowledge of cancer pain management should be strengthened among physicians. Quantitative pain assessment and principle-based pain management should be combined to achieve pain relief. Misconceptions about opioids in patients and physicians and poor report about pain should be overcome through training/education to improve QoL of patients impacted by pain.

Keywords: cancer pain, pain management, opioid drugs, questionnaires

\section{Introduction}

More than 10 million people are diagnosed with cancer worldwide every year, with this number set to increase to $>15$ million by $2020 .{ }^{1}$ A significant number of cancer patients worldwide will experience pain during the course of their disease. ${ }^{2,3} \mathrm{~A}$ total of $70 \%-80 \%$ of patients with cancers in progressive stages have been reported to suffer from moderate-to-severe pain. Untreated or undertreated pain intensity and duration significantly impair the quality of life (QoL). ${ }^{4-7}$ A survey in a comprehensive hospital of China that interviewed 427 physicians and 387 cancer pain patients reported inadequate pain assessment and analgesia for cancer pain. ${ }^{8}$ Another survey in 30 hospitals in 
Beijing, China, reported that pain was completely relieved in merely $9.48 \%$ of 589 cancer patients. ${ }^{9}$ Improving the outcome of cancer pain management in patients has become a challenge for Chinese medical professionals. The barriers to optimize the management of cancer pain frequently cited by professionals and patients included knowledge deficits, inadequate pain assessment and misconceptions regarding pain. ${ }^{10}$ When opioid drugs were involved, restrictive regulation of controlled substances, concern about addiction, tolerance and side effects were mentioned by both physicians and patients. ${ }^{10,11}$ Other factors included high costs (non-reimbursable expenses) and non-availability of treatment. ${ }^{11,12}$ It is well known that opioid administration has been the primary therapeutic method for the management of moderate-to-severe cancer pain. ${ }^{13}$ Jacobsen et $\mathrm{al}^{14}$ stated that the undertreatment of cancer pain could be caused by the barriers to the use of opioid analgesics. Caraceni et $\mathrm{al}^{6}$ reported evidence-based recommendations indicating that the skilled use of opioid analgesics is crucial to the relief of cancer pain. It must be noted that any approach of treating cancer pain might be impaired by numerous obstacles, such as access to medications and technologies and other factors that varied considerably from one country to another. ${ }^{15}$ Thus, it is essential to shed light on the current status of cancer pain management and guidance to improve therapeutic practices for the Chinese population.

The cross-sectional ACHEON survey, Current Practices of Cancer and Chronic Non-Cancer Pain Management: a pan-Asian study, represented the largest survey ever conducted on cancer pain management practices in Asia. ${ }^{16}$ This Asian survey received responses from 460 physicians in cancer-related fields and 1180 cancer patients from 10 Asian countries/regions, assessing clinical practices in cancer pain management (including mainland China, South Korea, Malaysia, Singapore, Philippines, Vietnam, Indonesia, Thailand, Hong Kong and Taiwan). ${ }^{16}$ The present study focused on the questionnaire data from 100 physicians and 250 patients surveyed in mainland China. To analyze the status about screening, assessment and treatment of cancer pain and to obtain physicians' and patients' perspectives with regard to cancer pain management, especially referring to opioid analgesics, we aimed at optimizing the outcome of cancer pain management.

\section{Materials and methods}

\section{Setting, sample and procedures}

Sampling was stratified by geographic region. Tertiary hospitals were selected from representative regions, including Shanghai (Eastern China), Beijing (Northern China), Guangzhou (Southeastern), Shenyang (Northeastern), Xi'an
(Northwestern), Chengdu (Southwestern) and Wuhan (Central China). A total of 100 physicians and 250 patients were selected from both oncology and pain departments. Recruitment methods used for patients included patient referral, doctor referral, hospital intercept, door-to-door recruitment or patient associations. Patients ( $>18$ years of age) who had experienced cancer pain for more than a month on admission were recruited with all cases pathologically confirmed. Patients experiencing pain that may have been caused by other reasons, those who had participated in other pain studies or those who were employees of pharmaceutical companies were excluded. Pain severity was evaluated by an 11-point Box Scale (BS-11) pain score of $0-10$, where 0 is no pain at all and 10 is the worst pain imaginable. Mild pain, moderate pain and severe pain were defined as $0-3,4-6$ and $7-10$ of BS-11 pain score, respectively. Physicians were randomly selected from databases of medical associations, official societies and national registries. All physicians included in the survey were required to have had at least 1 year of experience in the diagnosis and treatment of cancer pain.

The survey was conducted over 4 months (September 2013-December 2013) and carried out in accordance with the European Society for Opinion and Market Research (ESOMAR) code. No ethical approval was needed according to the Ethical Review of Biomedical Research Involving Human Beings (version 7 issued by National Health and Family Planning Commission of China). All physicians and patients involved in the survey have had their anonymity maintained and signed confidentiality agreements. All participants provided written informed consent before completing the survey questionnaire. Participation in the survey was voluntary, and investigators complied with both national and international laws while seeking to respect the rights and interests of the subjects surveyed.

\section{Survey questionnaire}

The ACHEON Physicians/Patient Questionnaire "Cancer Pain V1.0" (created by a steering committee consisting of 16 pain management experts) was used in the local language of the respective countries. Patients were administered the paper version or online version of the questionnaires to complete the quantitative 20-minute in-home interviews or at a location convenient to them. Physicians were scheduled for quantitative 20-minute interviews via telephone or faceto-face meetings at the physician's office.

The physicians' questionnaire data included 56 items about demographics (age, gender, profession, years of employment and training), pain assessment, pain management and attitudes (with regard to pain, pain assessment and pain management). 


\section{Data collection and data analyses}

The paper and electronic surveys were exported into Microsoft Excel sheets. A series of numerical rating scale (NRS, $0-10$ points) was used to assess attitudes toward cancer pain and clinical practice (pain screening, pain assessment and pain management with an emphasis on opioid analgesics). Here, NRS was just a 10-point scale. When the question was responded, NRS $>5$ denotes a response indicating adequacy or agreement, NRS $=5$ denotes a neutral response and NRS $<5$ denotes inadequacy or disagreement. The results of the surveyed questions were expressed as a percentage of NRS $>$ 5 , the median NRS and the interquartile range (IQR) of NRS. The possible answers in the questionnaires were either yes or no or a 5-point scale from totally agree to totally disagree. The analysis included descriptive summaries of categorical variables that are given as frequencies and percentage. The analysis included continuous variables of non-normal distribution that are presented as median and IQR.

\section{Results}

\section{General data of physicians and patients}

Flowchart of the survey design is shown in detail in Figure 1, showing that 100 physicians and 250 patients surveyed
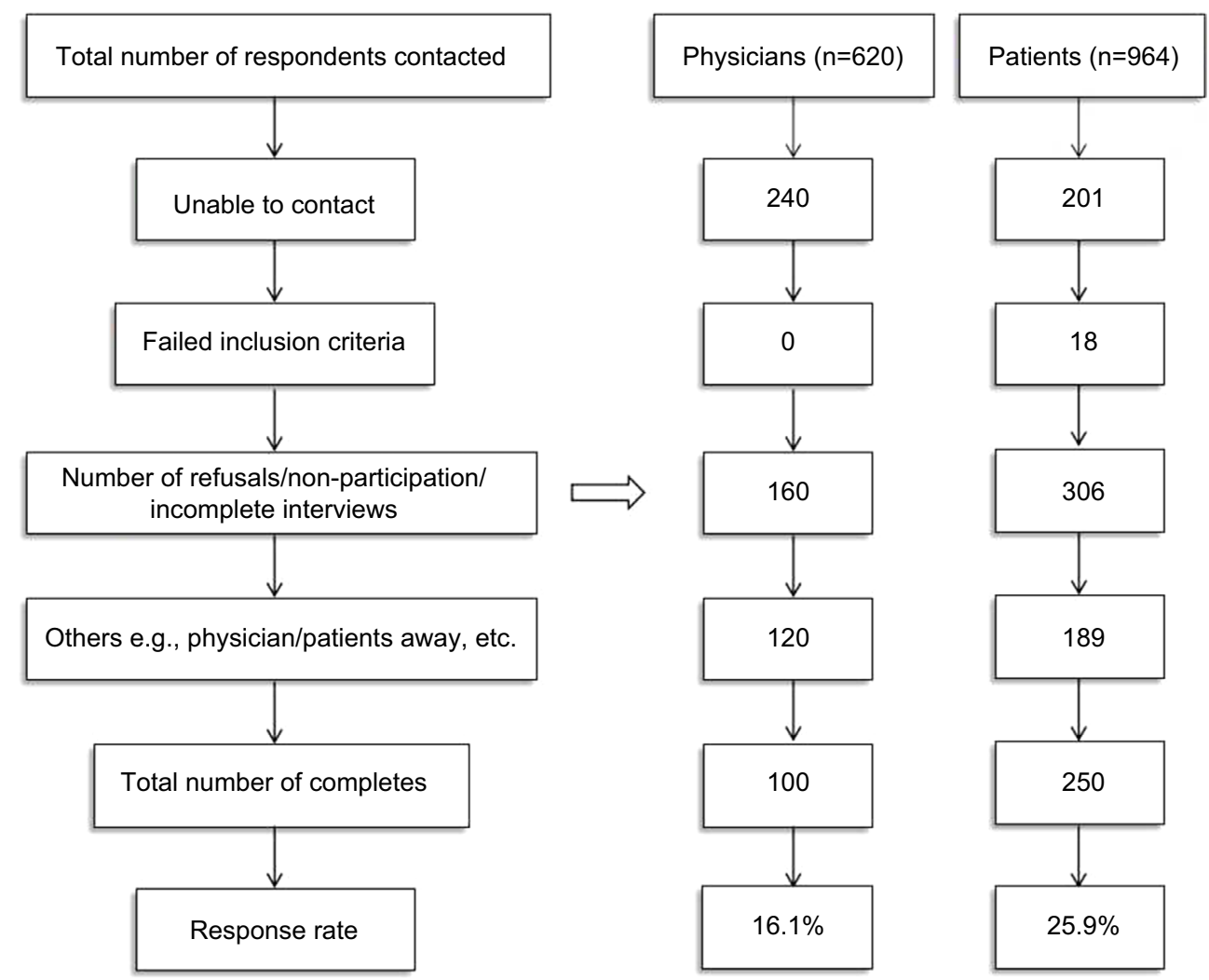

Figure I Flowchart of survey design, recruitment and selection phase of physicians and patients. completed the questionnaires in mainland China, with a response rate of $16.1 \%$ and $25.9 \%$.

Survey respondents' demographics of physicians are presented in detail in Table 1;98\% of physicians were medical/ hematological oncologists.

Survey respondents' demographics of patients are presented in detail in Table 2. Moderate-to-severe pain was reported in $88 \%$ of patients. The pain duration that exceeded 6 months was reported in $49.2 \%$ of patients.

\section{Perceptions of physicians on cancer pain management}

Perceptions of physicians could be acquired from Table 3 . When queried about the education/training with regard to cancer pain management, only $28 \%$ and $17 \%$ of physicians believed that their medical school and residency training was adequate. As for prescribing opioids for treating cancer pain, only $22 \%$ and $20 \%$ of physicians believed that their medical school and residency training was adequate; $38 \%$ of physicians received pain-related continuing medical education (CME) per year of $<10$ hours.

The majority of physicians considered it important to follow guidelines to manage cancer pain. National guideline was 
Table I Background information of physicians surveyed $(n=100)$

\begin{tabular}{ll}
\hline Parameters & Proportion \\
\hline Age (years) & \\
$20-39$ & $42 \%$ \\
$\geq 40$ & $58 \%$ \\
Gender & \\
Male & $50 \%$ \\
Female & $50 \%$ \\
Years in clinical practice & \\
Median (50\%), IQR & $15,9.5$ \\
I-5 & $4 \%$ \\
$6-10$ & $20 \%$ \\
II-20 & $51 \%$ \\
2 I-30 & $23 \%$ \\
$>30$ & $2 \%$ \\
Work environment & \\
Private practice & - \\
Teaching hospital & $32 \%$ \\
Community hospital/government hospital & $62 \%$ \\
Comprehensive cancer center & $6 \%$ \\
Specialization (cancer) & \\
Medical oncologist/hemato-oncologist & $98 \%$ \\
Surgical oncology & $2 \%$ \\
\hline
\end{tabular}

Abbreviation: IQR, interquartile range.

the top priority in $53 \%$ of physicians, followed by international guideline in $40 \%$ of physicians and hospital/practice-specific guideline in $7 \%$ of physicians. The concrete guidelines they adhered to are displayed in detail in Table 3.

In addition, $73 \%$ of physicians expressed that all patients were screened for pain on first and subsequent visits; $80 \%$ of physicians stated that they routinely assessed to quantify pain using pain scale for patients who present with pain. Besides BS-11 pain scale, physicians perceived that the pain assessment tools, shown in Figure S1A, can be used for patients who were unable to express a response in words due to cognitive or physical problems. However, $84 \%$ of physicians believed that intensity of pain experienced by patients was inconsistent with physicians' assessment.

Table 3 shows the perspectives of the physicians interviewed on questions about applying opioid drugs in cancer pain management. A total of $90 \%$ of physicians thought that opioid therapy is the first-line approach for the treatment of moderate-to-severe cancer pain.

\section{Perceptions of patients toward pain and pain treatment}

Perceptions of patients could be acquired from Table 4. Of the 250 patients surveyed, $80.8 \%$ expressed that the physician who was primarily responsible for their illness was a cancer specialist. Only $12 \%$ of patients surveyed were undertaken by a pain specialist; $73.2 \%$ of patients were asked about
Table 2 Background information of patients surveyed $(n=250)$

\begin{tabular}{|c|c|}
\hline Parameters & Proportion \\
\hline \multicolumn{2}{|l|}{ Age (years) } \\
\hline Mean & 60.7 \\
\hline Median, IQR & 62,18 \\
\hline$\leq 50$ & $22.8 \%$ \\
\hline $5 I-65$ & $36.0 \%$ \\
\hline$>65$ & $41.2 \%$ \\
\hline \multicolumn{2}{|l|}{ Gender } \\
\hline Female & $48.8 \%$ \\
\hline Male & $51.2 \%$ \\
\hline \multicolumn{2}{|l|}{ Education completed } \\
\hline Primary/elementary school & $47.2 \%$ \\
\hline High school & $39.2 \%$ \\
\hline Tertiary, bachelor's degree or above & $13.6 \%$ \\
\hline \multicolumn{2}{|c|}{ Current perceived level of pain (BS-I I pain scale score) } \\
\hline Median, IQR & 6,3 \\
\hline Mild pain $(0-3)$ & $12.0 \%$ \\
\hline Moderate pain (4-6) & $38.8 \%$ \\
\hline Severe pain $(7-10)$ & $49.2 \%$ \\
\hline \multicolumn{2}{|l|}{ Duration of pain (months) } \\
\hline Median, IQR & 6,9 \\
\hline$<3$ & $19.6 \%$ \\
\hline $3-6$ & $31.2 \%$ \\
\hline $6-12$ & $29.6 \%$ \\
\hline$>12$ & $19.6 \%$ \\
\hline \multicolumn{2}{|c|}{ Did your physician inform you of the cause of your cancer pain? } \\
\hline Yes & $94.4 \%$ \\
\hline No & $5.6 \%$ \\
\hline Related to cancer/tumor & $80 \%$ \\
\hline Related to chemotherapy/radiotherapy & $3.0 \%$ \\
\hline Related to both & $17.0 \%$ \\
\hline \multicolumn{2}{|l|}{ Primary physician responsible for cancer treatment } \\
\hline Cancer specialist & $80.8 \%$ \\
\hline Pain specialist & $12.0 \%$ \\
\hline Surgeon and general physician/practitioner & $7.2 \%$ \\
\hline
\end{tabular}

Abbreviation: IQR, interquartile range.

pain by their physicians at every visit, and $67.2 \%$ of patients expressed that a pain scale was used to assess pain intensity. The proportion of pain scale usage by physicians perceived by patients and physicians is shown in Figure S1B.

A total of $90 \%$ of patients were currently being treated for pain. The types of treatment patients received are shown in Table 4, including oral medicine, injectable medicine and transdermal patches. Of the 240 patients treated, $84.2 \%$ received oral administration, in line with the World Health Organization (WHO) guidelines stipulating oral administration as the primary choice. A total of $38.8 \%$ noted that their physicians had switched their pain medication at some stage, and 35.0\% actively requested to change pain medication. When patients were asked why they requested for change in medication, the explanations were as follows: the pain becoming more serious, a need for stronger analgesia, the occurrence of side effects, high cost and an unavailability of previously used drugs. 
Table 3 Physicians' perspectives on cancer pain management

\begin{tabular}{ll}
\hline Survey questions $(\mathbf{n}=\mathbf{1 0 0})$ & Proportion \\
\hline $\begin{array}{l}\text { Education/training } \\
\text { Do you feel that your medical school training with }\end{array}$ & $28 \%$ \\
$\begin{array}{l}\text { regard to cancer pain management was adequate? } \\
\text { Do you feel that your residency training in cancer }\end{array}$ & $17 \%$ \\
pain management was adequate? & \\
$\begin{array}{l}\text { Do you feel that your medical school training for } \\
\text { prescribing opioids (for managing cancer pain) was }\end{array}$ & $22 \%$ \\
adequate? & \\
$\begin{array}{l}\text { Do you feel that your residency training for } \\
\text { prescribing opioids (for managing cancer pain) was }\end{array}$ & $20 \%$ \\
adequate? & \\
How much pain-related CME do you receive per year? & \\
$\leq 10$ hours & $38 \%$ \\
$>10$ hours & $62 \%$
\end{tabular}

Do you believe that guidelines for pain management are important? Yes $\quad 97 \%$ No $\quad 3 \%$

At what level are pain management guidelines most appropriate? Hospital/practice specific $\quad 7 \%$ National $\quad 53 \%$ International $\quad 40 \%$

What guidelines do you adhere to? International guidelines $\quad 70 \%$ NCCN clinical practice guidelines in oncology $\quad 53 \%$ WHO 3-step analgesic ladder $\quad 21 \%$ EAPC guidelines $2 \%$ Western/European/American guidelines $\quad 2 \%$

Are all patients screened for pain on first and subsequent visits? Median, IQR

For patients who present with pain, did you routinely assess to quantify pain using pain scale?

$\begin{array}{ll}\text { Median, IQR } & 7.5,3.5 \\ \text { Usually "yes" }(6 \leq \mathrm{NRS} \leq 10) & 80 \% \\ \text { Usually "no" (I } \leq \mathrm{NRS} \leq 5) & 20 \%\end{array}$

Was intensity of pain experienced by patients inconsistent with physicians' assessment?

$\begin{array}{ll}\text { Median, IQR } & 7,2 \\ \text { Usually "yes" }(6 \leq \mathrm{NRS} \leq 10) & 84 \% \\ \text { Usually "no" (I } \leq \text { NRS } \leq 5) & 16 \%\end{array}$

Please mark your agreement with regard to your attitude on opioid usage in pain management

Opioid therapy is the first-line approach for treatment $\quad 90 \%(8,3)$

of moderate-to-severe cancer pain

Regularly scheduled opioid dosing is more effective $\quad 79 \%(8,3.5)$

than as needed dosing for chronic cancer pain

If opioid-related adverse effects are significant, an $\quad 87 \%(8,3)$

improved balance between analgesia and adverse

effects might be achieved by changing to an equivalent

dose of an alternative opioid

If side effects persist, consider opioid rotation

$83 \%(8,3.5)$

Notes: NRS $>5$ denotes a response indicating adequacy or agreement, NRS $=5$ denotes a neutral response and NRS $<5$ denotes inadequacy or disagreement. The survey results were expressed as a percentage of NRS $>5$, the median NRS and the IQR of NRS.

Abbreviations: CME, continuing medical education; NCCN, National Comprehensive Cancer Network; WHO, World Health Organization; EAPC, European Association for Palliative Care; IQR, interquartile range; NRS, numerical rating scale.
Table 4 Patients' perspectives on screening, assessment and treatment of pain

\section{Survey questions}

Proportion

How did you describe physician who is primarily responsible for your illness? $(n=250)$

Cancer specialist $\quad 80.8 \%$

Pain specialist

$12.0 \%$

Surgeon/general physician/general practitioner $\quad 7.2 \%$

What is the frequency of visits to primary physician (cancer)? $(n=250)$

More than once a month $\quad 71.6 \%$

Once a month $\quad 19.2 \%$

Less than once every 3 months $\quad 9.2 \%$

What is the frequency of questioning with regard to pain by physician? $(\mathrm{n}=250)$

At every visit $\quad 73.2 \%$

At less than half of the visits $\quad 16.4 \%$

At more than half of the visits $\quad 7.6 \%$

Only occasionally $2.8 \%$

Did the physician use pain scale to assess pain? $(n=250)$

Yes 67.2\%

No $\quad 32.8 \%$

Are you being treated for pain? $(n=250)$

Yes

$90.0 \%$

No

$10.0 \%$

What types of treatment did you receive? $(n=240)$

Oral medicine (tablets, syrups) $\quad 84.2 \%$

Injectable medicine $\quad 19.6 \%$

Transdermal patches $\quad 13.8 \%$

Traditional Chinese medicine $\quad 15.0 \%$

Interventional pain medication/physical therapy $\quad 12.1 \%$

(massage, heat, hydrotherapy)/psychological therapy

How many types of treatment did you receive? $(n=240)$

One option 67.1\%

More than one option $\quad 32.9 \%$

Did your physician change pain medication before?

$(n=240)$

Yes $\quad 38.8 \%$

No $\quad 52.9 \%$

Do not know $\quad 8.3 \%$

Did you request to change pain medication? $(n=240)$

Yes $\quad 35.0 \%$

No $\quad 65.0 \%$

Could you recall the type of pain treatment received? $(n=240)$

Yes $61.3 \%$

No $\quad 38.7 \%$

What were you prescribed with? $(n=147)$

Opioids $\quad 83.7 \%$

Non-opioid painkillers (includes analgesics, NSAIDs) $\quad 28.6 \%$

Have you experienced constipation due to opioid use? $(n=123)$

Yes $\quad 82.9 \%$

No $\quad 17.1 \%$

Have you taken laxatives as a result of opioid-induced constipation? $(n=123)$

Yes $\quad 70.7 \%$

No $\quad 29.3 \%$

What types of side effects due to pain medication did you have? $(\mathrm{n}=240)$

Nausea/vomiting $\quad 32.5 \%$

Sleepiness/drowsiness $\quad 15.4 \%$

Dizziness/giddiness $\quad 11.7 \%$

Tiredness $\quad 12.1 \%$

Abbreviation: NSAIDs, nonsteroidal anti-inflammatory drugs. 
Of the 147 patients who recalled the medication received, $83.7 \%$ were administered opioid prescriptions and $28.6 \%$ received non-opioid analgesics (including nonsteroidal antiinflammatory drugs). Of the 123 patients who took opioids, $82.9 \%$ experienced constipation due to opioid use and $70.7 \%$ had taken laxatives as a result of opioid-induced constipation. Other side effects due to pain medication were prevalent in patients, such as nausea/vomiting, sleepiness/drowsiness, dizziness/giddiness and tiredness (Table 4).

\section{Outcome and barriers of pain management and impact of pain on patients' life}

Of the 240 patients who received therapy, $51.7 \%$ reported satisfaction with treatment and $43.8 \%$ reported that current treatment was inadequate for controlling pain. When unrelieved pain was told to physicians by patients, the corresponding proportion of patients claimed that dose adjustments, the addition of other analgesics, switching of analgesic drugs and referral to another physician were advised by physicians, as shown in Table 5 .

Several aspects of daily life that were affected due to pain were reported by patients, as shown in Table 5, such as sleeping pattern, concentration and focus. In addition, 86.8\% of patients reported unemployment. Affected performance at work by pain and discontinued work due to pain were common in $13.2 \%$ of patients who were employed (Table 5).

In the perspectives of physicians interviewed, barriers to optimize management of cancer pain (especially with regard to opioids) arose from three aspects shown in Figure 2: patients, physicians and regulatory/policy system. The primary barriers included patients' fear of side effects (58\%), patients' fear of addiction (53\%), patients' reluctance to report pain (43\%), physicians' reluctance to prescribe (29\%), physicians' inadequacy of pain assessment $(27 \%)$ and excessive management of opioids $(47 \%)$.

\section{Discussion}

This study presented the clinical practices of cancer pain management in a cross-sectional survey in mainland China, derived from ACHEON survey in Asia. ${ }^{16}$ Despite proactive pain screening, quantitative pain assessment and guidelinebased treatment reported by physicians, underestimate of pain intensity and inadequacy of pain control were reported by patients surveyed.

\section{Pain assessment}

In this survey, $88 \%$ of patients reported moderate-to-severe pain. This result confirmed that pain was still prevalent in
Table 5 Outcome of pain management and impact of pain on patients' life

\begin{tabular}{|c|c|}
\hline Parameters & Proportion \\
\hline \multicolumn{2}{|c|}{$\begin{array}{l}\text { Please indicate your level of satisfaction with your current treatment } \\
(n=240)\end{array}$} \\
\hline Satisfied & $51.7 \%$ \\
\hline Neutral & $45.0 \%$ \\
\hline Not satisfied & $3.3 \%$ \\
\hline \multicolumn{2}{|c|}{$\begin{array}{l}\text { Is your current treatment inadequate for controlling your pain? } \\
(n=240)\end{array}$} \\
\hline Yes & $43.8 \%$ \\
\hline No & $56.2 \%$ \\
\hline \multicolumn{2}{|c|}{$\begin{array}{l}\text { How has your doctor responded after being informed that your } \\
\text { pain is not being sufficiently treated? }(n=105)\end{array}$} \\
\hline Yes & $99.0 \%$ \\
\hline No & $1 \%$ \\
\hline \multicolumn{2}{|c|}{$\begin{array}{l}\text { What did physician do when he/she was told pain was not } \\
\text { uncontrolled? }(n=104)\end{array}$} \\
\hline Adjusts the dose of my pain medication & $60.6 \%$ \\
\hline Adds another pain medication & $46.2 \%$ \\
\hline Switches pain medication & $28.7 \%$ \\
\hline Refers me to another physician & $4.8 \%$ \\
\hline \multicolumn{2}{|l|}{ Does pain affect daily living? $(n=250)$} \\
\hline Yes & $80.8 \%$ \\
\hline No & $19.2 \%$ \\
\hline \multicolumn{2}{|l|}{ Aspects of daily life affected $(n=202)$} \\
\hline My pain affects my sleeping pattern & $92.6 \%$ \\
\hline My pain affects my concentration and focus & $90.6 \%$ \\
\hline My pain forces me to rely too much on other people & $81.2 \%$ \\
\hline My pain affects my activities of daily living & $93.1 \%$ \\
\hline Overall, my pain does not allow me to have a good QoL & $64.9 \%$ \\
\hline \multicolumn{2}{|l|}{ Are you employed? $(n=250)$} \\
\hline Yes & $13.2 \%$ \\
\hline No & $86.8 \%$ \\
\hline \multicolumn{2}{|l|}{ My pain impacts my performance at work $(n=33)$} \\
\hline Agree somewhat/completely & $87.9 \%$ \\
\hline \multicolumn{2}{|l|}{ How many days did you miss for work? $(n=33)$} \\
\hline$<7$ days & $21.21 \%$ \\
\hline $7-14$ days & $15.15 \%$ \\
\hline 15-28 days & $3.03 \%$ \\
\hline$>28$ days & $60.61 \%$ \\
\hline
\end{tabular}

Abbreviation: QoL, quality of life.

cancer patients. Pain assessment is the cornerstone to quality pain management. ${ }^{17,18}$ Thus, accurately assessing pain challenged health care workers since no objective measures exist. ${ }^{18}$ The intensity of pain was measured by the patient's self-report. ${ }^{19}$ Our data here showed that $84 \%$ of the surveyed physicians perceived the inconsistence of pain assessed by clinical physicians and experienced by patients.

On the one hand, this result strengthened the necessity of use of pain scale by physicians. However, our data here showed that $32.8 \%$ of patients and $20 \%$ of physicians revealed that pain scale was not used when assessing pain. The reason was not explained. About $27 \%$ of physicians perceived no adequate pain assessment of clinicians worsened optimal 


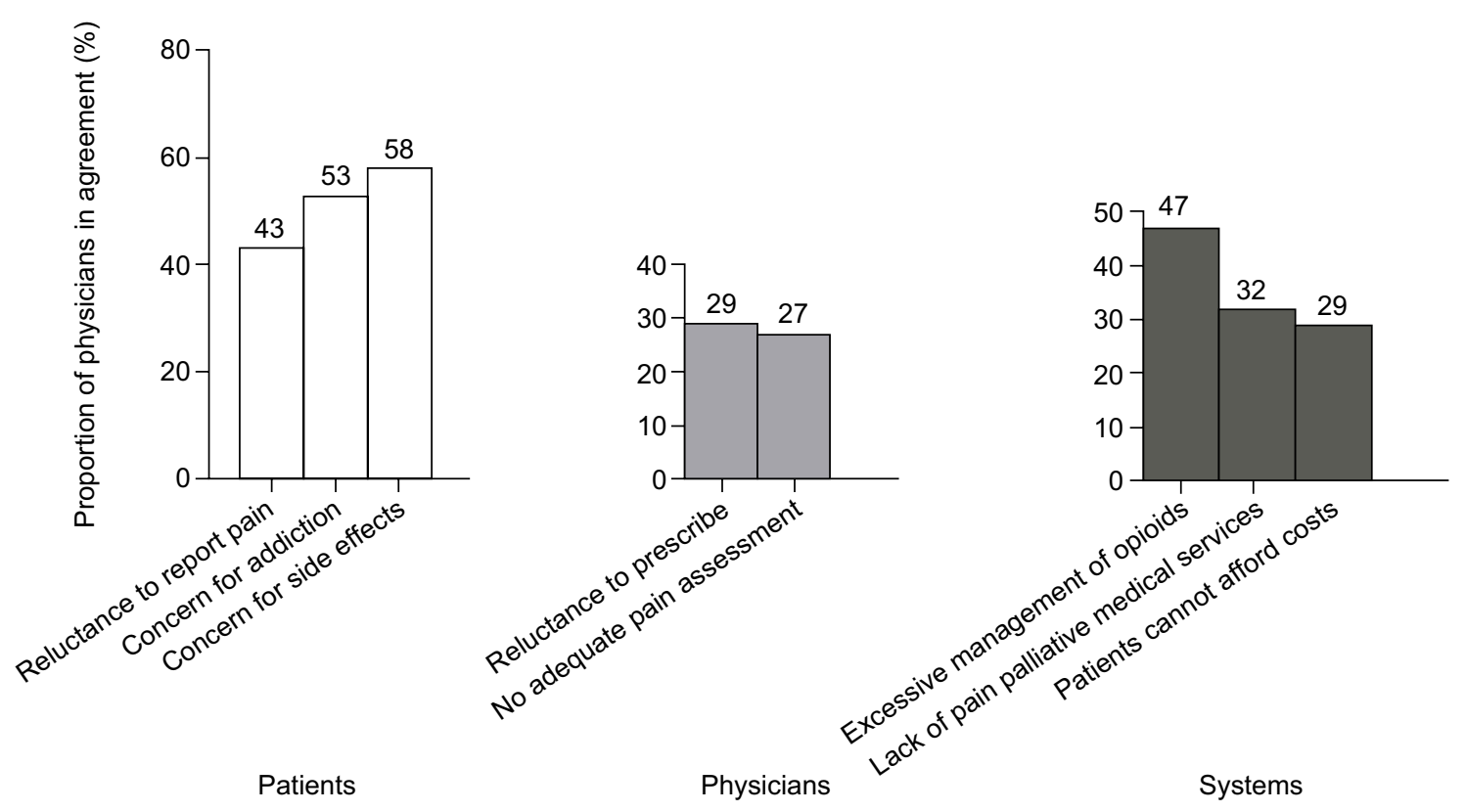

Figure 2 Barriers to pain management from physicians' perspective $(n=100)$.

pain management. The most commonly used pain assessment scales included NRS, visual analog scale (VAS) and verbal rating scale (VRS). ${ }^{20}$ The BS-11 scale used in our survey, sometimes otherwise known as NRS, is a standard pain scale that is widely used as a standardized scoring system to assess patient's perceived levels of pain experienced. In our survey, the physicians interviewed also mentioned that a variety of behavioral pain assessment tools played a role in quantifying pain for nonverbal patients due to cognitive or physical problems, such as The Assessment of Discomfort in Dementia Protocol (ADD) and Checklist of Nonverbal Pain Indicators (CNPI).

On the other hand, the earlier result strengthened the necessity of effective expression about pain by patients. Patients in certain Asian countries have been reported to be more able to endure pain and to delay seeking help until pain becomes severe. ${ }^{21}$ In the ACHEON survey, $52.5 \%$ of 463 physicians in Asia perceived that reluctance to report pain as patient-related factor was an important barrier to optimization of therapy. ${ }^{16}$ In our survey, $43 \%$ of 100 physicians perceived patient's reluctance to report pain. Green and Hart-Johnson ${ }^{18}$ claimed that patients with the same pain problem and seemingly similar pain severity often report differences in pain experience. Patient pain training should be noted to improve patient-physician and patient-nurse communication about pain intensity. ${ }^{22}$

A previous report showed that patients suffered from unnecessary pain durations due to insufficient pain assessments. ${ }^{23}$ Medical staff should therefore seek to further strengthen pain assessment practices, including comprehen- sive and dynamic assessments, and endeavor to follow up on time after hospital discharge.

\section{Training/education on pain management}

Opioid drugs are the mainstay of analgesics for moderateto-severe pain and consequently are the focus for many guidelines. $^{22}$ In our survey, $90 \%$ of physicians similarly perceived that opioid therapy was the first-line approach for the treatment of moderate-to-severe cancer pain.

As for training/education, although the majority of physicians perceived the inadequacy of medical school/residency training for prescribing opioids (for managing cancer pain), only $38 \%$ of physicians surveyed received $\leq 10$ hours of CME training on cancer pain management per year. In addition, $12 \%$ of patients reported that their pain was treated through referral to pain specialist. These results suggested the inadequate training in pain management and the lack of pain specialist. A national survey of US medical oncologists showed the importance of opioid to manage pain and suggested prevalent deficits in knowledge about opioids. ${ }^{24} \mathrm{~A}$ survey of physicians in southwest China reported insufficient training in pain control. ${ }^{25}$ Another survey of physicians in four tertiary hospitals of China indicated that creating training opportunities for medical staff was necessary to improve cancer pain management practices. ${ }^{26}$

On the use of opioids for cancer pain, many guidelines were developed to assist in the pain management at both national and international levels, such as WHO 3-step analgesic ladder and European Association for Palliative Care (EAPC) guidelines. ${ }^{6,27}$ The undertreated pain was still often 
interpreted as a result of lack of adequate clinical guidelines or a failure to properly implement and comply with the available guidelines. ${ }^{28}$ Thus, the training content should include pharmacological information on opioid drugs and evidencebased instruction on how to choose and use them.

\section{Optimizing treatment of cancer pain}

In our survey, $83.7 \%$ of the 147 patients who recalled the medication received were administered opioids prescription; however, $45 \%$ or $3.3 \%$ of 240 patients perceived that the level of satisfaction with current treatment was neutral or not satisfied. Dissatisfaction mainly attribute to that pain medications have not relieved pain. As a previous study reported, physicians in mainland China failed to take advantage of opioid analgesics to relieve cancer pain..$^{29}$ The poor medication adherence or no achievement to the optimal drug dosage could possibly induce pain not well controlled.

Our questionnaire data presented physicians' perceived barriers to optimize cancer pain management in mainland China. First, physicians surveyed focused on patient-related factor resulting in barriers. In our survey, besides reluctance to report pain, patients' reluctance to take opioids caused by their concern about addiction and side effects was perceived by $53 \%$ and $58 \%$ of physicians. The beliefs of patients about using pain medication have an impact on the treatment they received.$^{30}$ In some cases, patients were to be persuaded to receive opioid analgesics or even they refused opioids despite unbearable pain. Many patients considered tolerance and physical dependence as equivalent to psychological addiction. ${ }^{30}$ Porter and Jick ${ }^{31}$ reported the risk of opioid drug addiction as $<4$ in 10000 (4/11882 cases), indicating that opioid addiction was extremely rare in patients with no history of drug abuse. With the application of controlledrelease opioids, around-the-clock medication may effectively mitigate high peak blood concentrations and reduce the risk of addiction. Given opioid-related adverse effects (particularly constipation), the corresponding treatments were recommended during the course of pain medication. Our survey indicated that $70.7 \%$ of 123 patients prescribed with opioids had also taken laxatives.

Second, physicians paid attention to clinician-related and system-related factors resulting in barriers. In our survey, besides physicians' inadequate pain assessment mentioned earlier, $29 \%$ of physicians perceived the physicians' reluctance to prescribe. About $47 \%$ of physicians perceived that there was excessive management of opioids by government's policy. Cherny et al stated that physicians should be able to prescribe opioids according to the individual needs of each patient. However, laws and regulations in many countries interfered with the medical availability of opioids for the relief of pain. Opioid availability continued to be low throughout most of Asia. ${ }^{32,33}$ Compared with Japan, South Korea, Hong Kong, Nepal, Malaysia, Vietnam, and Thailand, mainland China presented more governmental regulatory policies to prescribe opioids, leading to inadequate opioid access for cancer pain relief. ${ }^{34}$ These findings were contradictory to those in Western countries. United States presented major increases in opioid analgesic abuse, mainly due to a growing availability of prescription opioids. ${ }^{35}$ Thus, the coordination at the governmental level was needed to balance opioid analgesic control and medical use of opioids. In addition, $32 \%$ of physicians perceived the lack of pain palliative medical services in mainland China. Just as reported, palliative medicine was in infancy in China and faced many challenges. ${ }^{29}$

Our data were generated by qualitative questionnaires designed to cover a variety of scenarios in clinical practice of cancer pain management, including screening, assessment, general treatment, management of associated symptoms and issues. We acknowledge that some of the data had constraints and limitations, such as patients' recall bias and physicians' answers to cater to social expectations. Moreover, complications were not assessed in order to streamline the survey. However, we believe that this survey in mainland China nevertheless provided a good indicator of current clinical practices.

\section{Conclusion}

Professional training/education for physicians and pain knowledge spreading for patients are critical to improve management of cancer pain. This will require a strengthening of cancer pain assessment methods and the use of opioid drugs in a rational and standardized manner to further improve the efficacy of cancer pain control and QoL for patients with cancer.

\section{Acknowledgments}

This survey was sponsored by Mundipharma Pte Ltd, Singapore. Mundipharma was the sponsor of the research, participated in the development of the survey protocol and funding of survey conduct, data analysis and medical writing services. The author and the sponsor thank The Research Partnership Healthcare Asia Pte Ltd for survey conduct and data analysis and Beijing Preintell Biomed Co., Ltd for medical writing assistance, funded by Mundipharma (China) Pharmaceutical Co., Ltd. A special thanks to all physicians and patients for their participation in the survey. 


\section{Disclosure}

The author reports no conflicts of interest in this work.

\section{References}

1. Johnson JR, Lossignol D, Burnell-Nugent M, Fallon MT. An open-label extension study to investigate the long-term safety and tolerability of THC/CBD oromucosal spray and oromucosal THC spray in patients with terminal cancer-related pain refractory to strong opioid analgesics. J Pain Symptom Manage. 2013;46(2):207-218.

2. Goudas LC, Bloch R, Gialeli-Goudas M, Lau J, Carr DB. The epidemiology of cancer pain. Cancer Invest. 2005;23(2):182-190.

3. Van den Beuken-van Everdingen M, De Rijke J, Kessels A, Schouten H, Van Kleef M, Patijn J. Prevalence of pain in patients with cancer: a systematic review of the past 40 years. Ann Oncol. 2007;18(9):1437-1449.

4. van den Beuken-van MH, de Rijke JM, Kessels AG, Schouten HC, van Kleef M, Patijn J. High prevalence of pain in patients with cancer in a large population-based study in The Netherlands. Pain. 2007;132(3):312-320.

5. Deng D, Fu L, Zhao YX, et al. The relationship between cancer pain and quality of life in patients newly admitted to Wuhan Hospice Center of China. Am J Hosp Palliat Care. 2012;29(1):53-59.

6. Caraceni A, Hanks G, Kaasa S, et al. Use of opioid analgesics in the treatment of cancer pain: evidence-based recommendations from the EAPC. Lancet Oncol. 2012;13(2):e58-e68.

7. Ferrell BR. The impact of pain on quality of life. A decade of research. Nurs Clin North Am. 1995;30(4):609-624.

8. Yu S, Wang XS, Cheng Y, Yang J, Cleeland CS. Special aspects of cancer pain management in a Chinese general hospital. Eur J Pain. 2001;5(suppl A): 15-20.

9. Ding Y, Yang P, Sun L-Q, Lu Y-H, Zhang L. Pain management among hospitalized cancer patients: a survey in 30 hospitals in Beijing. Chin J Nurs. 2011;3:26.

10. Oldenmenger WH, Smitt PAS, van Dooren S, Stoter G, van der Rijt CC. A systematic review on barriers hindering adequate cancer pain management and interventions to reduce them: a critical appraisal. Eur J Cancer. 2009;45(8):1370-1380.

11. Sun VC-Y, Borneman T, Ferrell B, Piper B, Koczywas M, Choi K. Overcoming barriers to cancer pain management: an institutional change model. J Pain Symptom Manage. 2007;34(4):359-369.

12. Kwon JH. Overcoming barriers in cancer pain management. $J$ Clin Oncol. 2014;32(16):1727-1733.

13. Mercadante S, Porzio G, Ferrera P, et al. Sustained-release oral morphine versus transdermal fentanyl and oral methadone in cancer pain management. Eur J Pain. 2008;12(8):1040-1046.

14. Jacobsen R, Møldrup C, Christrup L, Sjøgren P. Patient-related barriers to cancer pain management: a systematic exploratory review. Scand J Caring Sci. 2009;23(1):190-208.

15. Burton AW, Hamid B. Current challenges in cancer pain management: does the WHO ladder approach still have relevance? Expert Rev Anticancer Ther. 2007;7(11):1501-1502.

16. Kim YC, Ahn JS, Calimag MMP, et al. Current practices in cancer pain management in Asia: a survey of patients and physicians across 10 countries. Cancer Med. 2015;4(8):1196-1204.

17. Fink R. Pain assessment: the cornerstone to optimal pain management. Paper presented at: Baylor University Medical Center. Proceedings; 2000.
18. Green CR, Hart-Johnson T. The adequacy of chronic pain management prior to presenting at a tertiary care pain center: the role of patient socio-demographic characteristics. J Pain. 2010;11(8):746-754.

19. Herr K, Coyne PJ, Key T, et al; American Society for Pain Management Nursing. Pain assessment in the nonverbal patient: position statement with clinical practice recommendations. Pain Manage Nurs. 2006;7(2):44-52.

20. Hjermstad MJ, Fayers PM, Haugen DF, et al; European Palliative Care Research Collaborative (EPCRC). Studies comparing Numerical Rating Scales, Verbal Rating Scales, and Visual Analogue Scales for assessment of pain intensity in adults: a systematic literature review. $J$ Pain Symptom Manage. 2011;41(6):1073-1093.

21. Im EO, Liu Y, Kim YH, Chee W. Asian American cancer patients' pain experience. Cancer Nurs. 2008;31(3):E17-E23.

22. Syrjala KL, Abrams JR, Polissar NL, et al. Patient training in cancer pain management using integrated print and video materials: a multisite randomized controlled trial. Pain. 2008;135(1):175-186.

23. Jacobsen R, Sjogren P, Moldrup C, Christrup L. Physician-related barriers to cancer pain management with opioid analgesics: a systematic review. J Opioid Manag. 2007;3(4):207-214.

24. Breuer B, Fleishman SB, Cruciani RA, Portenoy RK. Medical oncologists' attitudes and practice in cancer pain management: a national survey. J Clin Oncol. 2011;29(36):4769-4775.

25. Liao Z, Hao J, Guo Y, Reyes-Gibby C, Guo H. Assessment of cancer pain management knowledge in southwest China: a survey of 259 physicians from small city and county hospitals. $J$ Palliat Med. 2013;16(6):692-695.

26. Yanjun S, Changli W, Ling W, et al. A survey on physician knowledge and attitudes towards clinical use of morphine for cancer pain treatment in China. Support Care Cancer. 2010;18(11):1455-1460.

27. Breivik H, Cherny N, Collett B, et al. Cancer-related pain: a panEuropean survey of prevalence, treatment, and patient attitudes. Ann Oncol. 2009;20(8):1420-1433.

28. Pigni A, Brunelli C, Gibbins J, et al. Content development for EUROPEAN GUIDELINES on the use of opioids for cancer pain: a systematic review and Expert Consensus Study. Minerva Anestesiol. 2010;76(10):833.

29. Li J, Davis MP, Gamier P. Palliative medicine: barriers and developments in mainland China. Curr Oncol Rep. 2011;13(4):290-294.

30. Cohen E, Botti M, Hanna B, Leach S, Boyd S, Robbins J. Pain beliefs and pain management of oncology patients. Cancer Nurs. 2008;31(2):E1-E8.

31. Porter J, Jick H. Addiction rare in patients treated with narcotics. $N$ Engl J Med. 1980;302(2):123.

32. Cherny N, Cleary J, Scholten W, Radbruch L, Torode J. The Global Opioid Policy Initiative (GOPI) project to evaluate the availability and accessibility of opioids for the management of cancer pain in Africa, Asia, Latin America and the Caribbean, and the Middle East: introduction and methodology. Ann Oncol. 2013;24(suppl 11):xi7-xi13.

33. Manjiani D, Paul DB, Kunnumpurath S, Kaye AD, Vadivelu N. Availability and utilization of opioids for pain management: global issues. Ochsner J. 2014;14(2):208-215.

34. Cleary J, Radbruch L, Torode J, Cherny N. Formulary availability and regulatory barriers to accessibility of opioids for cancer pain in Asia: a report from the Global Opioid Policy Initiative (GOPI). Ann Oncol. 2013;24(supp1 11):xi24-xi32.

35. Compton WM, Volkow ND. Major increases in opioid analgesic abuse in the United States: concerns and strategies. Drug Alcohol Depend. 2006;81(2):103-107. 


\section{Supplementary material}

A

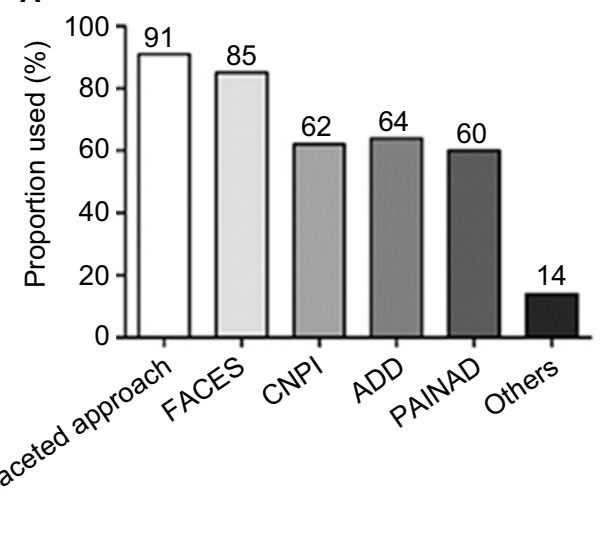

B

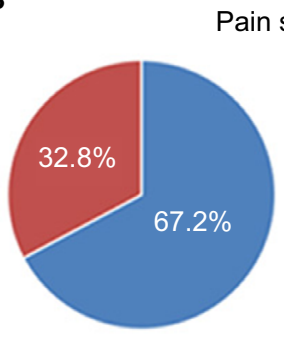

Patients $(n=250)$

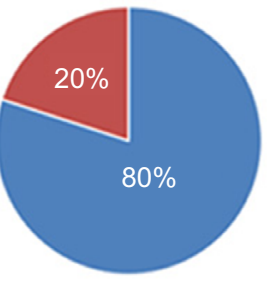

Physicians $(n=100)$

= Used

" Not used

Figure SI Practices of pain assessment.

Notes: $(\mathbf{A})$ Pain assessment tools employed by physicians $(n=100)$. Multifaceted approaches included direct observation, description by family members or caregivers. (B) Frequency of usage of a pain scale to assess cancer pain, as reported by patients and physicians.

Abbreviations: FACES, facial expression scale; CNPI, Checklist of Nonverbal Pain Indicators; ADD, Assessment of Discomfort in Dementia Protocol; PAINAD, Pain Assessment in Advanced Dementia Scale.

\section{Publish your work in this journal}

The Journal of Pain Research is an international, peer reviewed, open access, online journal that welcomes laboratory and clinical findings in the fields of pain research and the prevention and management of pain. Original research, reviews, symposium reports, hypothesis formation and commentaries are all considered for publication.

\section{Dovepress}

The manuscript management system is completely online and includes a very quick and fair peer-review system, which is all easy to use. Visit http://www.dovepress.com/testimonials.php to read real quotes from published authors. 